\title{
SISTEM INFORMASI MANAJEMEN PERSEDIAAN BARANG DI BENGKEL KIMS MOTOR DEPOK
}

\author{
Ahmad Agung Gumilar \\ Teknik Informatika, Fakultas Teknik dan Ilmu Komputer, Universitas Indraprasta PGRI \\ Jl. Raya Tengah No. 80, Kel. Gedong, Kec. Pasar Rebo, Jakarta Timur, Indonesia 13760 \\ agunggumilarahmad@gmail.com
}

\begin{abstract}
ABSTRAK
Bengkel KIMS Motor merupakan suatu usaha yang bergerak pada bidang penjualan suku cadang dan pelayanan service motor. Bengkel KIMS Motor menyediakan berbagai perawatan, perbaikan dan penjualan sukucadang serta memberikan pelayanan yang optimal bagi pelanggan. Tujuan penelitian ini adalah untuk merancang suatu sistem manajemen persediaan barang dan pelayanan yang dapat mempermudah dalam proses penjualan sukucadang dan mengelola data service menjadi lebih cepat, efektif, dan efisien. Metode penelitian yang digunakan dalam perancangan sistem penjualan suku cadang dan service pada Bengkel KIMS Motor yaitu Research and Development (R\&D) dan pengembangan sistemnya menggunakan metode waterfall. Sedangkan dalam teknik pengumpulan data yang digunakan meliputi wawancara, observasi, serta melakukan penelitian kepustakaan yang relevan dengan sistem penjualan suku cadang dan service. Hasil dari penelitian ini adalah perancangan sistem terkomputerisasi dibangun dengan menggunakan bahasa pemrograman Java Netbeans dan database MySQL. Dengan menggunakan sistem terkomputerisasi memudahkan karyawan bengkel dalam melakukan pencatatan transaksi, mempermudah pihak bengkel dalam mengetahui jumlah stok suku cadang, proses pembuatan laporan dapat dilakukan dengan cepat dan akurat.
\end{abstract}

Kata Kunci: Penjualan, Sistem Informasi, Suku Cadang, Bengkel

\begin{abstract}
Bengkel KIMS Motor is a business that is engaged in the sale of spare parts and motorcycle service services. Bengkel KIMS Motor provides a variety of maintenance, repair and sales of spare parts and provides optimal service for customers. The purpose of this study is to design an inventory management system and services that can facilitate the process of selling sukucadangs and managing data services to be faster, more effective, and efficient. The research method used in designing the spare parts and service sales system at the Bengkel KIMS Motor is Research and Development $(R \& D)$ and the system development uses the waterfall method. Whereas the data collection techniques used include interviews, observations, and conducting library research relevant to the sukucadangs sales and service system. The result of this research is the design of a computerized system built using the Java Netbeans programming language and MySQL database. By using a computerized system, it makes it easier for workshop employees to record transactions, make it easier for the workshop to find out the amount of spare parts stock, the reporting process can be done quickly and accurately.
\end{abstract}

Key Word: Sales, Information Systems, Spare Parts, Workshop

\section{PENDAHULUAN}

Perkembangan peranan ilmu pengetahuan dan teknologi yang semakin maju saat ini berpengaruh terhadap kemajuan bisnis usaha, baik secara individual, instansi pemerintah, ataupun swasta. Salah satu perkembangan teknologi maju adalah komputer. Dengan menggunakan komputer tidak perlu lagi menghitung dan menganalisa data secara manual, selain itu data atau informasi yang diperoleh dari komputer lebih cepat dan akurat dengan perancangan suatu sistem.
Fathansyah (2012) menyatakan bahwa Sistem ialah sebuah keterpaduan atau tatanan yang terdiri dari beberapa komponen fungsional (dengan satuan tugas atau fungsi khusus ) dan saling berhubungan secara bersama-sama yang mempunyai tujuan untuk memenuhi suatu pekerjaan atau proses tertentu. Sedangkan Azhar Susanto (2013) menyatakan bahwa Sistem adalah kumpulan / group dari sub sistem/komponen apa saja baik fisik maupun non fisik yang saling berhubungan satu dengan yang lain dan saling bekerja sama secara terpadu untuk mencapai tujuan tertentu. 
Yakub (2012) menyatakan bahwa Perancangan Sistem didefinisikan sebagai perencanaan, pembuatan dan penggambaran sketsa ataupun pengaturan beberapa elemen yang terpisah menjadi kesatuan yang berfungsi secara utuh. "Informasi merupakan kumpulan data yang diolah menjadi bentuk yang lebih berguna dan lebih berarti bagi yang menerima. Tanpa suatu informasi, suatu sistem tidak akan berjalan dengan lancar dan akhirnya bisa mati" (Kristanto, 2018).

Darmawan (2013:2) menjelaskan bahwa informasi merupakan hasil dari pengolahan data, akan tetapi tidak semua hasil dari pengolahan tersebut bisa menjadi informasi, hasil pengolahan data yang tidak memberikan makna atau arti serta tidak bermanfaat bagi seseorang bukanlah merupakan informasi bagi orang tersebut. Dari kutipan di atas pengertian informasi penulis mengambil kesimpulan bahwa informasi adalah data yang telah diolah menjadi sebuah bentuk yang lebih berguna dan bermanfaat bagi yang menerimanya.

Kotler \& Keller (2020) menjelaskan bahwa produk adalah segala sesuatu yang dapat ditawarkan kepada pasar untuk memuaskan suatu keinginan atau kebutuhan, termasuk barang fisik, jasa, pengalaman, acara, orang, tempat, properti, organisasi, informasi, dan ide. Salah satu jenis usaha dibidang penjualan sukucadang dan service motor sangat memerlukan adanya sistem pengolahan data untuk mempermudah dan memperlancar kinerja penjualannya, saat ini masih banyak pencatatan data-data penjualan dan service dengan buku dan kalkulator, baik itu transaksi ataupun pembuatan laporan sehingga membuat kinerja bengkel menjadi kurang efektif dan efisien, maka dari itu peneliti ingin membuat perancangan sistem penjualan sukucadang dan service.

Berdasarkan latar belakang di atas, maka rumusan masalahnya adalah bagaimana mengatasi kesulitan dalam mengontrol stok sukucadang yang ada di bengkel, bagaimana mengatasi kesulitan dalam membuat laporan, bagaimana mengefisienkan proses transaksi penjualan, bagaimana membuat perancangan sistem penjualan yang mampu melakukan proses pencatatan yang masih manual menjadi terkomputerisasi.

Manfaat yang didapat dari hasil penelitian ini adalah mempermudah pihak bengkel dalam mengetahui jumlah stok sukucadang, mempercepat melakukan transaksi penjualan yang dapat digunakan untuk pencatatan transaksi penjualan sukucadang yang terkomputerisasi, membantu dalam membuat laporan sukucadang agar lebih efektif dan efisien, menghasilkan sistem yang terkomputerisasi serta memudahkan karyawan bengkel dalam melakukan pencatatan transaksi.

\section{METODE PENELITIAN}

Tempat Penelitian dilakukan pada KIMS MOTOR yang beralamatkan di Jl. Bambon No. 29 Rt 002/006 Kel. Ragajaya Kec. Bojong Gede, Kabupaten Bogor.

Desain yang digunakan dalam penelitian ini yaitu metode air terjun atau yang sering disebut metode waterfall. Metode ini sering diberi nama siklus hidup klasik, dimana dalam hal ini menggambarkan suatu pendekatan yang berurutan dan juga sistematis pada pengembangan perangkat lunak, dimulai dari kebutuhan spesifikasi si pengguna lalu berlanjut melalui suatu tahapan-tahapan perencanaan (planning), permodelan (modeling), konstruksi (construction), serta penmberian sistem kepada pengguna (deployment), diakhiri dengan memberikan dukungan pada perangkat lunak yang dihasilkan secara lengkap(Pressman, 2012).

\section{Metode Wawancara}

Teknik wawancara yang digunakan dalam penelitian ini adalah menggunakan teknik wawancara yang terstruktur. Maksudnya adalah proses wawancara dilakukan secara terencana, dalam hal ini peneliti terlebih dahulu menyiapkan interview guide sebagai panduan dalam mewawancarai informan untuk mendapatkan informasi yang berkaitan dengan cara kerja sistem dokumentasi Bengkel KIMS Motor serta hal-hal yang berkaitan dengan materi yang akan dibahas dalam penulisan tugas akhir ini. Informan yang akan peneliti wawancarai adalah mekanik bengkel. 


\section{Metode Observasi}

Observasi adalah melakukan pengamatan dan pencatatan secara sistematik kepada unsurunsur yang muncul dalam suatu gejala dalam bentuk objek penelitian. Mendefinisikan observasi untuk memilih, mengubah dan juga pengodean serangkaian perilaku dalam susasana sesuai dengan tujuan empiris (Hikmat, 2011).

Dalam metode ini, peneliti melakukan pengumpulan data yang diperlukan dengan cara melakukan pengamatan langsung terhadap sistem dokumentasi Bengkel KIMS Motor. Peneliti juga melakukan pencatatan data yang sesuai dengan fakta yang mendukung dalam penyusunan tugas akhir yang didapat dari pengumpulan data pada Bengkel KIMS Motor.

\section{HASIL DAN PEMBAHASAN}

Data flow diagram atau dalam bahasa Indonesia adalah Diagram Alir Data (DAD) adalah suatu model logika atau proses yang dibuat untuk menggambarkan dari mana asal data dan kemana tujuan data yang keluar dari sistem, dimana data disimpan, proses apa yang menghasilkan data tersebut dan interaksi antara data yang tersimpan dan proses yang dikenakan pada data tersebut.

Penulis menggunakan Diagram Alir Data (DAD) untuk merancang sistem penilaian kinerja di PDAM Tirta Patriot Bekasi. Menurut Ladjamudin (2013) "Diagram Alir Data merupakan model dari sistem untuk menggambarkan pembagian sistem ke modul yang lebih besar".

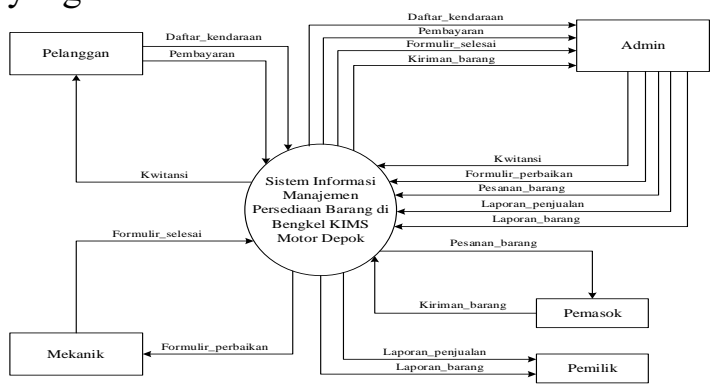

Gambar 1. Diagram Konteks Sistem Berjalan

Analisis permasalahan yang dapat disimpulkan dari hasil penelitian pada Bengkel KIMS Motor bahwa bengkel ini masih mengunakan sistem masukan data yang manual, kurang efisien dalam waktu, biaya dan pengerjaan laporan dikarenakan lamanya pencarian data di dalam buku catatan, kesalahan data dalam perhitungan dan pembuatan nota kurang efektif dalam proses transaksi karena semua dibuat dengan manual, data laporan serta informasi yang disajikan kurang lengkap dan akurat.

Alternatif penyelesaian masalah yang peneliti usulkan dengan perancangan sistem informasi manajemen persediaan barang yang mendukung proses perhitungan agar proses penjualan dapat dilakukan dengan cepat dan akurat, dapat mengetahui jumlah stok sukucadang yang tersisa dengan mudah dan cepat, membuat database yang sistematis sehingga memudahkan dalam pencarian data yang dibutuhkan dalam pembuatan laporan, perancangan sistem penjualan sukucadang dan service pada Bengkel KIMS Motor dibangun dengan menggunakan bahasa pemrograman Java Netbeans dengan menggunakan database MySQL.

Hubungan antar data digambarkan dalam bentuk ERD (Entity Relationship Diagram). Menurut Ariani Sukamto \& Shalahuddin, (2015) pemodelan basis data yang paling banyak digunakan adalah menggunakan Entity Relationship Diagram (ERD). ERD digunakan untuk pemodelan basis data relasional. Tujuan dari ERD ini adalah menunjukkan objek data dan relationship yang ada pada objek tersebut. Adapun ERD untuk KIMS MOTOR Depok adalah :

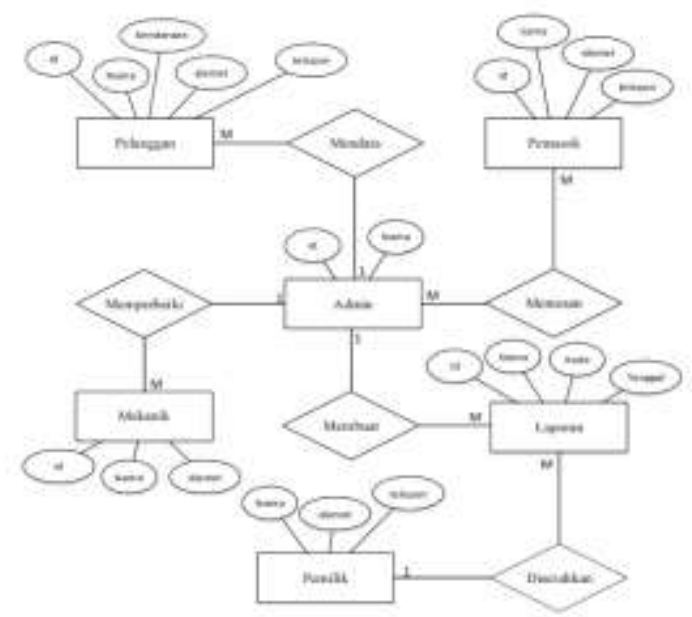

Gambar 2. Entity Relationship Diagram 


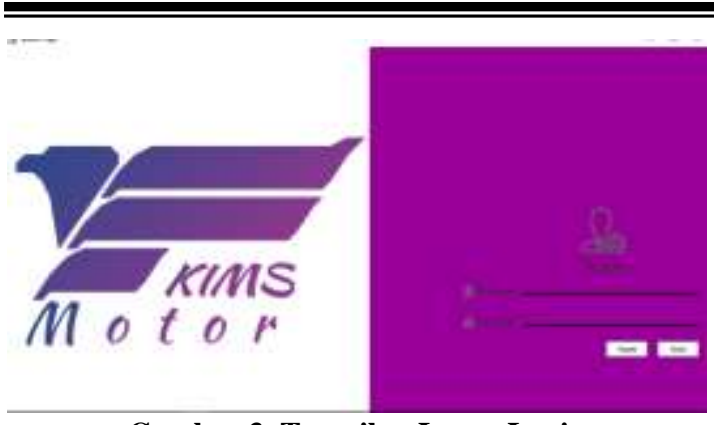

Gambar 3. Tampilan Layar Login

Tampilan layar login terdiri dari menu username, password, masuk dan keluar. Apabila user ingin masuk ke dalam aplikasi, maka harus memasukkan username dan password terlebih dahulu kemudian klik tombol masuk.

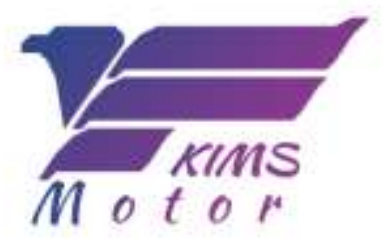

Gambar 4. Tampilan Layar Menu Utama

Pada halaman menu utama terdapat tiga kategori yang digunakan yaitu Data Master, Data Transaksi, dan laporan.

Berikut ini adalah hasil keluaran (printout) yang nanti hasilnya dapat menjadi laporan manual kepada pemilik bengkel.

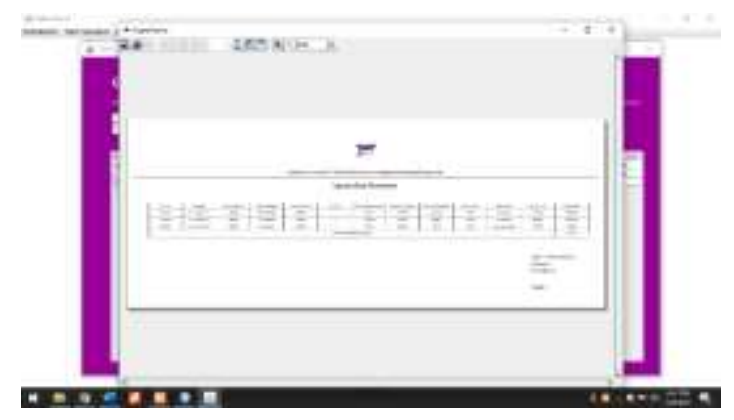

Gambar 5. Tampilan Laporan Pemasukan

Laporan data Pemasukan ini didapat dari datadata penjualan yang sudah diinput admin ke dalam database yang nantinya diserahkan kepada pemilik bengkel.

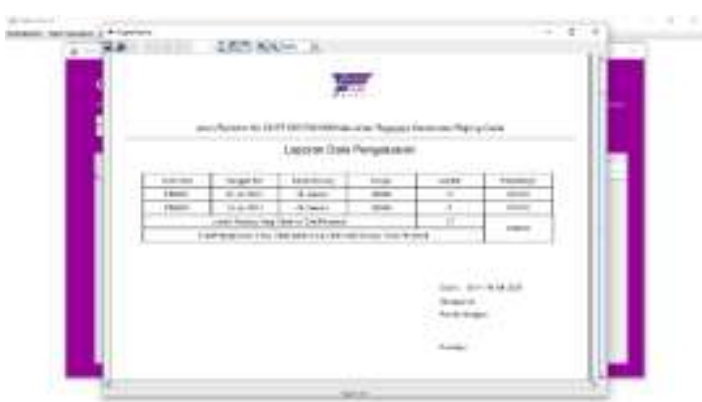

Gambar 6. Tampilan Laporan Pengeluaran

Laporan data Pengeluaran ini didapat dari data-data penjualan yang sudah diinput admin ke dalam database yang nantinya diserahkan kepada pemilik bengkel.

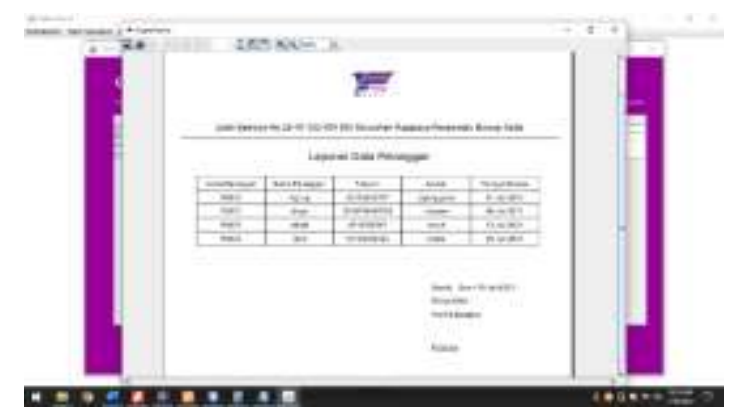

Gambar 7. Tampilan Laporan Pelanggan

Laporan data Pelanggan ini didapat dari datadata penjualan yang sudah diinput admin ke dalam database yang nantinya diserahkan kepada pemilik bengkel.

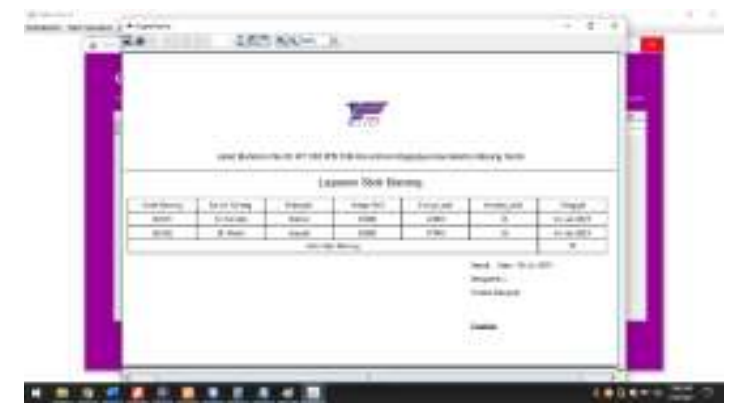

Gambar 8. Tampilan Laporan Stok Barang

Laporan data Stok Barang ini didapat dari data-data penjualan yang sudah diinput admin ke dalam database yang nantinya diserahkan kepada pemilik bengkel.

\section{SIMPULAN DAN SARAN}

Berdasarkan perancangan sistem informasi manajemen yang telah dibuat oleh penelti untuk memenuhi kebutuhan dan menjawab masalah yang ada pada Bengkel KIMS Motor, 
peneliti dapat simpulkan dengan

menggunakan sistem komputerisasi maka

Bengkel KIMS Motor dapat mengetahui jumlah stok sukucadang yang tersisa dengan mudah dan cepat. Hal ini dikarenakan proses pencarian stok dapat dilihat menurut kode sukucadang. Pengolahan data penjualan sukucadang dan service Bengkel KIMS Motor lebih efektif serta keamanan terhadap data lebih terjamin serta pembuatan laporan dapat dilakukan dengan cepat dan akurat, memudahkan admin untuk memantau atau mengontrol data yang ada dalam database. Aplikasi masih dapat dikembangkan dengan menambahkan beberapa posisi seperti kasir, pembantu mekanik, dll.

\section{DAFTAR PUSTAKA}

Al-Bahra Bin Ladjamudin. (2013). Analisis dan Desain Sistem Informasi. Graha Ilmu.

Ariani Sukamto, R., \& Shalahuddin, M. (2015). Rekayasa Perangkat Lunak Terstruktur dan Berorientasi Objek. Bandung: Informatika. informatika.

Darmawan, D. D. (2013). Sistem informasi manajemen. Remaja Rosdakarya.

Fathansyah. (2012). Basis Data Edisi Revisi. Informatika.

Hikmat, M. M. (2011). Metode penelitian: dalam perspektif ilmu komunikasi dan sastra. Graha Ilmu.

Kotler, Philip; Keller, K. L. (2020). Manajemen pemasaran: Jil. 1/ Philip Kotler, Kevin Lane Keller; alih bahasa Bob Sabran. Management Studies and Entrepreneurship.

Kristanto, A. (2018). Perancangan Sistem Informasi dan Aplikasinya. Penerbit Gava Media.

Pressman, R. S. (2012). Rekayasa perangkat lunak:pendekatan praktisi ed.7. Andi.

Susanto, A. (2013). Sistem Informasi Akuntansi. Lingga Jaya.

Yakub. (2012). Pengantar sistem informasi. Graha Ilmu. 